\section{G397(P) REDUCING TRANSFUSION AND UNNECESSARY SKIN PUNCTURE IN THE PREMATURE NEWBORN}

${ }^{1}$ A Jiwani, ${ }^{1,2}$ JC Becher. ${ }^{1}$ University of Edinburgh, Edinburgh, UK; ${ }^{2}$ Simpsons Special Care for Babies Neonatal Unit, Royal Infirmary Edinburgh, UK

10.1136/archdischild-2018-rcpch.386

Background Quality improvement and standardisation are important drivers for healthcare, particularly within neonatology where future improvements in outcome will be increasingly delivered by the optimisation of marginal gains across a wide range of practice.

Aim The primary aim of this study is to reduce skin punctures and iatrogenic blood loss in a high-risk group of infants. There were three key objectives of this project; namely to investigate the problem, educate staff and implement change.

Methods The project utilised a variety of Methods feasibility of 'point of care' (POC) testing versus laboratory testing, case study comparison, and an exploratory analysis of staff knowledge of appropriate blood volumes. Data supporting the use of minimal volumes for POC blood analysis was presented and an educational (P) for all neonatal areas was developed. This $(\mathrm{P})$ was then surveyed to determine if a change in bloodletting resulted.

Results We showed that by using POC testing that approximately $82 \%$ of babies can be spared additional blood tests and approximately $55 \%$ of blood tests can be avoided. We showed that in the initial survey $46 \%$ of staff overestimated and 14\% underestimated blood volumes required for laboratory analysis and in the repeated survey $56 \%$ of staff overestimated and $12 \%$ underestimated blood volumes required for laboratory analysis. Limitations to the results were revealed as the $(\mathrm{P}) \mathrm{s}$ were removed from within the neonatal unit bed space and placed in the blood gas analyser room. Staff verbally stated that $(\mathrm{P})$ s within the unit were very helpful during the blood-letting procedure. Thus, we showed the benefit of visual aids for appropriate blood volumes in premature newborns. We showed that by adopting a conservative approach to central line placement and blood sampling that babies could avoid excessive blood testing and skin punctures.

Conclusion In a vulnerable group of neonatal patients, changes to practice, education and culture may reduce unnecessary blood sampling. This may lead to a reduction in infection and blood sampling thus, reducing need for blood transfusion.

\section{G398(P) FAST AND METICULOUS: IMPROVING QUALITY OF NEONATAL RESUSCITATION DOCUMENTATION}

M Karam, N Merchant, S Narayanan. Department of Paediatrics and Neonatology, West Hertfordshire NHS Trust, London, UK

10.1136/archdischild-2018-rcpch.387

Introduction Neonatal resuscitation is a fast-paced event that requires cohesive team working and effective multidisciplinary communication. Accurate event documentation is vital for clinical care and has medico-legal implications.

Aim To improve neonatal resuscitation documentation.

Methods One year review of neonatal encephalopathy cases identified a common theme of poor resuscitation documentation (Phase 0). Using quality improvement(QI) methodology (table 1) interventions were implemented in iterative PDSA cycles. Following this, a review of 12 randomly selected resuscitation notes were conducted from July-Dec 2016 (Phase I) and following responsive interventions to findings, a repeat audt was carried out between Aug-Oct 17 (Phase II). Results were analysed in Microsoft Excel.

Results Use of proforma had increased to $73 \%$ by phase II. There was $100 \%$ documentation of interventions and observations in both phase I and II (table 2). Perinatal staff expressed satisfaction and acceptance of the record form, noting ease of use

\begin{tabular}{|c|c|c|c|}
\hline Aim & Primary drivers & Secondary drivers & Change ideas \\
\hline \multirow[t]{11}{*}{$\begin{array}{l}50 \% \text { improvement in use } \\
\text { of resuscitation } \\
\text { proforma }\end{array}$} & COMMUNICATION & $\begin{array}{l}\text { Interface } \\
\text { communication }\end{array}$ & $\begin{array}{l}\text { Streamline } \\
\text { crash call } \\
\text { codes }\end{array}$ \\
\hline & & Team debrief & Neonatal \\
\hline & & & SBAR \\
\hline & BETTER QUALITY & Equipment/paperwork & Resuscitaire \\
\hline & CARE & & $\begin{array}{l}\text { log check } 12 \\
\text { hrly }\end{array}$ \\
\hline & & Adherence to NLS & NLS training \\
\hline & & sequence & $\begin{array}{l}\text { Induction } \\
\text { updates }\end{array}$ \\
\hline & BETTER & Increase awareness of & (P) campaign \\
\hline & DOCUMENTATION & $\begin{array}{l}\text { resuscitation } \\
\text { proforma }\end{array}$ & \\
\hline & & $\begin{array}{l}\text { Adherence to } \\
\text { documentation }\end{array}$ & $\begin{array}{l}\text { Targeted } \\
\text { simulation }\end{array}$ \\
\hline & & standards & training \\
\hline
\end{tabular}

Abstract G398(P) Table 2 Improvement in resuscitation scribe documentation

\begin{tabular}{llll}
\hline & Phase 0 & Phase I(\%) & Phase II(\%) \\
\hline Random case notes & 9 & 12 & 11 \\
Proforma & 0 & 50 & 73 \\
Documentation of interventions & N/A & 100 & 100 \\
Documentation of observations & N/A & 100 & 100 \\
Team Names and Roles & N/A & 33 & 75 \\
Parental Communication & N/A & 17 & 38 \\
Signed and dated & N/A & 33 & 50 \\
\hline
\end{tabular}

Conclusion Through collaborative working and intelligent use of QI methodology >50\% improvement in quality of neonatal resuscitation documentation was demonstrate. Further work is needed to improve documentation of team roles and parental communication.

\section{G399(P) TRAINEE LEADS}

S Akbar, S Cassim, J Ngai, C McCullough, G Alam, J Stewart, K Medjoub, H Smith Aberdeen Royal Infirmary, NHS Grampian, Aberdeen, UK

\subsection{6/archdischild-2018-rcpch.388}

Background/motivation The Trainee Lead (TL) initiative was devised by the Medical Education Team to bridge the gap between trainees and management and empower trainees to become involved in improvement processes. 